\title{
Diurnal variations in the aerosol physical, optical and altitude distributional characteristics over three locations in eastern India: Implications to black carbon radiative forcing
}

\author{
Niranjan Kandula, Sreekanth Vakacherla*, Mahesh Bade, and S. Kiranmayi \\ Department of Physics, Andhra University, Visakhapatnam, India
}

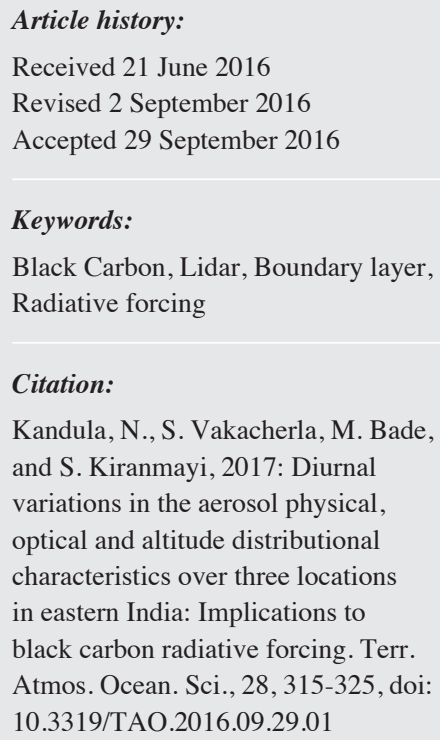

\begin{abstract}
A qualitative assessment on the effect of boundary layer dynamics in the estimation of clear sky black carbon (BC) radiative forcing has been made considering the debate on the lower bound and possible uncertainties in the aerosol radiative forcing estimation. Comprehensive measurements made on aerosol optical and physical properties, near surface BC mass concentrations and Lidar derived aerosol back scatter intensity profiles at three selected locations in India (Visakhapatnam, Kharagpur, and Kolkata) are utilized for this purpose. Sensitivity analysis carried out to estimate the errors in short wave (SW) BC forcing computation indicated that nonincorporation of diurnal changes in the boundary layer depth into the models may lead to over estimation of diurnally averaged (as the study is limited to short wave radiative forcing, diurnally averaged forcing refers to day-time averaged) $\mathrm{BC}$ forcing. The relative errors may vary between 7 to $70 \%$ depending on the season and the location changes in boundary layer depth day-time behaviour. The results reported in the present study, though specific to the study locations, clearly indicate that a more systematic approach is needed to investigate the sensitivity of aerosol radiative forcing to various atmospheric parameters and processes within the boundary layer, particularly at stations characterised by strong anthropogenic influence and large diurnal temperature variability that affect the boundary layer depth.
\end{abstract}

\section{INTRODUCTION}

Direct aerosol radiative forcing (DARF) indicates the change in radiative flux at the top of the atmosphere due to the presence of aerosols. It is one of the crucial parameters for assessing the potential impacts of aerosols originating from particulate emissions as well as secondary sources like Volatile Organic Compounds (VOCs). DARF is still not properly quantified nor the processes well understood at the level of detail necessary (Henze et al. 2012). The changes in the radiative forcing due to the varying aerosol burden and their composition are important factors that determine the optical state of the atmosphere at a given time and the radiative fluxes are dependent on the entire atmospheric column that interacts with the solar radiation (Bush and Valero 2003). Black carbon (BC) aerosol, being a strong absorber of solar radiation, leads to substantial atmospheric

\footnotetext{
* Corresponding author

E-mail: sree_hcu@yahoo.co.in
}

heating with a global mean top of atmosphere (TOA) radiative forcing less than about $1 \mathrm{~W} \mathrm{~m}^{-2}$ (Wang 2004, 2007). However, the accompanying surface cooling along with other combined climate system responses to the radiative thermodynamic effect makes this heating relatively inefficient in elevating the global mean surface temperature. The balance of impacts from absorption in relation to scattering aerosols is highly dependent on the sector/region with respect to the emission scenarios as well as the emissions transportation to and from the particular locations considered (Henze et al. 2012). The aerosol load over south Asia builds up in winter and the pre-monsoon dry season in the presence of stable boundary layer inversion and the transport of pollutants over the region tends to double the aerosol load compared to that during the summer months (Smith et al. 2001). Niranjan et al. (2012) indicated that the aerosol radiative forcing over coastal urban India largely depends on the relative mass concentration of $\mathrm{BC}$ and sulphate aerosol. It was observed that the composite forcing at the top of the 
atmosphere follows the $\mathrm{BC}$ mass concentration during all seasons and that $\mathrm{BC}$ either independently or in the internal mixture state would determine the composite forcing. Bauer et al. (2010) reported that the mass absorption strength and the scattering ability of $\mathrm{BC}$ particles depends on their size and chemical composition and it was estimated that internal mixing enhances the $\mathrm{BC}$ absorption by a factor 1.5 to 1.6.

Changes in regional stability caused by atmospheric heating of the light-absorbing aerosols may alter the largescale circulation and the hydrological cycle, which underscore the need to understand the role of aerosol light absorption in climate change, which requires realistic inclusion of $\mathrm{BC}$ aerosol radiative forcing (Kirchstetter et al. 2004). Wang (2007) reported that the BC-forced changes in atmospheric circulation are represented by a strengthened Hadley cell in the northern hemisphere, a weakened one in the southern hemisphere, an enhancement of the Indian summer monsoon circulation, and a reduction in low level easterly wind in the central and east pacific equatorial region.

Stevens (2015) suggested a rethinking on the lower bound of the aerosol radiative forcing, reported that model parameters randomly drawn to represent the uncertainty in understanding demonstrate that a global mean forcing of $1.0 \mathrm{~W} \mathrm{~m}^{-2}$ is implausible considering the rate of temperature rise. The tropospheric aerosol radiative forcing overestimation might probably be the result of incorporating the aerosol processes that remain sensitive to a large number of poorly constrained assumptions (Hoose et al. 2009; Golaz et al. 2011; Boucher et al. 2013). Furthermore, Wang et al. (2015) indicated that in heavily polluted regions with a strong diurnal variation in aerosol abundance, the use of diurnally averaged values could affect the aerosol radiative forcing estimation with a percent error varying between 0.1 and 28.5. With these points in mind, it is important to assess the accuracies with which the surface measurements in conjunction with column optical depths can yield BC aerosol radiative forcing without considering the aerosol altitudinal information. In this context, we have revisited our earlier experimental observations to carry out a study on the sensitivity of aerosol $\mathrm{BC}$ radiative forcing estimation to the variation in mixed-layer height. Utilizing the abovementioned campaign mode aerosol measurements, Niranjan et al. (2006) presented the winter-time surface and columnar aerosol temporal characteristics and their vertical mixing (across the boundary layer height) over Kharagpur (KGP).

\section{DATA}

Comprehensive aerosol, optical and physical properties measurements were carried out at two selected locations in the eastern India viz., $\mathrm{KGP}\left(22.31^{\circ} \mathrm{N}, 87.31^{\circ} \mathrm{E}\right)$, a station located in the outflow region of the Indo-Gangetic Plains (IGP) and Visakhapatnam (VSP; $17.7^{\circ} \mathrm{N}, 83.3^{\circ} \mathrm{E}$ ) on the southern peninsula of India. KGP is located just at the mouth of the pollution outflow vent from the north Indian region into the Bay of Bengal (BoB). The measurements were carried at the Regional Remote Sensing Centre (RRSSC) of the Indian Space Research Organization (ISRO) located in the Indian Institute of Technology, Kharagpur, as part of the ISRO-GBP Land Campaign II during the $1^{\text {st }}$ to $27^{\text {th }}$ of December 2004. KGP is a small town with cement, iron, and steel manufacturing industrial units. VSP is an industrialized urban coastal location on the east coast of India with an industrial area in the south-west and is very close to the $\mathrm{BoB}$ coast ( $\sim 500 \mathrm{~m}$ away) and predominantly subjected to sea-breeze activity on all days. The measurements at VSP were carried out during the years 2004 and 2005 at the Department of Physics, Andhra University. In addition, representative measurements were also made at Kolkata (KOL). KOL is located on the East coast of India and the measurements were carried out at the University of Calcutta for three days from 28 - 30 December 2004. It is the third largest urban agglomerate and fourth largest city in India with high suspended particulate matter levels when compared to other major cities, leading to regular smog and haze. In light of the data availability for a fewer number of days over KOL, the results obtained over KOL are used to compare and contrast against the other two stations. Figure 1 illustrates the geographical locations of the study areas. More details on the site descriptions are given elsewhere (Niranjan et al. 2006, 2012).

\subsection{Measurements and Instrumentation}

The measurements include the (1) aerosol optical depths (AODs) at 5 wavelengths centred at $0.38,0.44,0.5$, $0.675,0.87 \mu \mathrm{m}$ using a MICROTOPS II Sun photometer (Solar Light Co., United States; procured in January 2004), with a Global Positioning System (GPS) receiver attached to the photometer to provide information on the location,

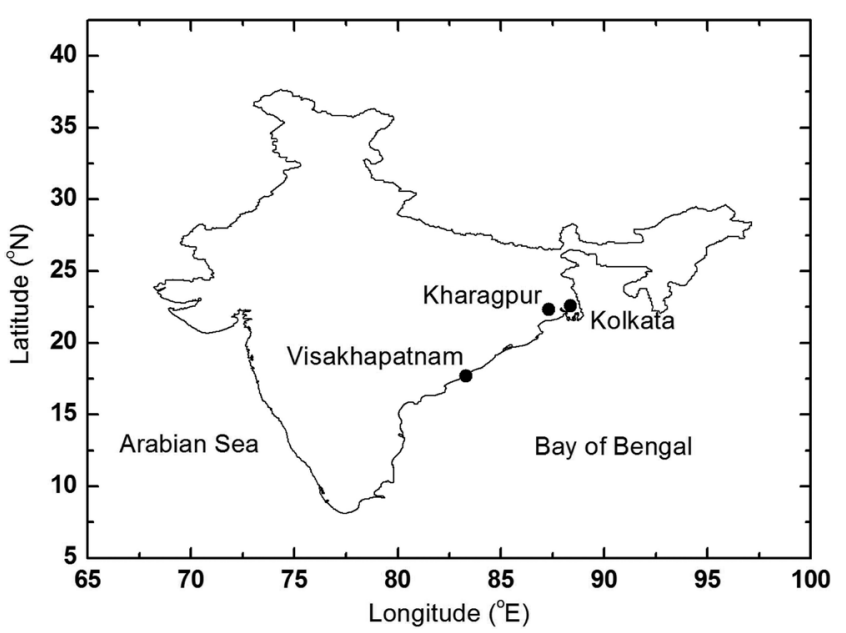

Fig. 1. Map showing the geographical spots of the study locations Visakhapatnam (VSP), Kharagpur (KGP), and Kolkata (KOL). 
altitude, and pressure (Morys et al. 2001); (2) near real time $\mathrm{BC}$ mass concentration using a seven channel Aethalometer (Magee Scientific, United States); and (3) vertical profiles of aerosol backscatter intensity using a SESI Micro Pulse Lidar (MPL) system, which employs an optical transceiver that acts as both transmitter and receiver (telescope) consisting of a pulsating Nd: YLF laser, Si-APD photon counting detector, signal processing unit, and data processor (multichannel scalar). The wavelength used for the measurement is $532 \mathrm{~nm}$ green light, which is the second harmonic of the laser's fundamental wavelength of $1064 \mathrm{~nm}$. The detailed aerosol properties and the radiative effects from these two stations were independently reported earlier (Niranjan et al. 2006, 2007; Sreekanth et al. 2007; Madhavan et al. 2008). Niranjan et al. $(2006,2007)$ and Madhavan et al. (2008) dealt with aerosol general and sporadic aspects and temporal characteristics, which include AOD, BC, Lidar, and chemical composition measurements. Sreekanth et al. (2007) derived seasonal BC forcing (over VSP) using offline models assuming a mean boundary layer height. The prime idea of the present study is to compare the winter time observations from both stations, which show significant diurnal variations in aerosol properties, and investigate whether the changes in the boundary layer altitude affect the DARF estimation from the experimental observations using a suite of instruments. The current study is advancement to all earlier studies mentioned above.

Regarding the error estimates, typical combined error in AOD measurement using the Microtops II sunphotometer as described by Porter et al. (2001) and Ichoku et al. (2002) is in the range $0.009-0.011$ at different wavelengths, which is negligible considering the high AODs measured at the locations. The Microtops instrument used in the present study was imported in the year 2004, which was just new with factory settings and calibration, when the measurements reported here were made. The BC mass was estimated from the light attenuation transmitted through a filter tape and the optical attenuation is converted into $\mathrm{BC}$ mass using a specific absorption efficiency of $16.6 \mathrm{~m}^{2} \mathrm{~g}^{-1}$ (Hansen 1996). Considering the present configuration for data acquisition, the uncertainty in the $\mathrm{BC}$ mass concentration estimation is in the range $40-60 \mathrm{ng} \mathrm{m}^{-3}$ for each measurement at 5 minute intervals for the set flow rate of 3 LPM (litres per minute).
Detailed data deduction technique and error budgets with the Aethalometer used in the present configuration were given by Babu and Moorthy (2002) and Babu et al. (2002). A detailed description of the corrections applied to the raw backscatter signal from the MPL was presented in Niranjan et al. (2006, 2007). Table 1 gives a summary of measurement periods and parameters over the study locations.

\section{RESULTS}

\subsection{Spectral AODs}

Knowledge on the spectral dependence of AOD is important for adequately modeling the aerosols effects on the radiation budget of the Earth-atmosphere system or for accurately retrieving the aerosol optical parameters from satellite remote sensors (Eck et al. 1999). Figures 2a, b, and c represent the typical winter-time diurnal variation in AODs over VSP, KGP and KOL at 0.38, 0.5, and 0.87, respectively, on typical clear sky observation day. It can be seen that the temporal variations of $\tau_{0.38}, \tau_{0.5}$, and $\tau_{0.85}$ over KOL are higher and more unstable all through the day with the peak value at noon and thereafter steeply decreased by evening. Over KGP and VSP, the diurnal variation remained stable showing contrasting features after $1400 \mathrm{LT}$ with a sharp increase in AODs over VSP. By evening, the AOD values at VSP resembled the AOD values observed over KOL in the morning. Singh et al. (2004) studied the diurnal variability of AOD over Kanpur, northern India and found it to increase at noon and decrease in the afternoon during all seasons. They attributed this phenomenon to the diurnal cycle of local pollutants arising from anthropogenic activities. Devara et al. (1996) reported on the ratio between afternoon and forenoon AOD showing greater than 1.0 in pre-monsoon and less than 1.0 in winter season over Pune in western India. Generally, aerosol forcing estimates are made using either instantaneous or daytime mean aerosol optical properties for simulating fluxes with and without aerosols. Mean seasonal diurnal variability over different geographical regions is valuable information to take into account while using instantaneous AOD data to assess the aerosol radiative forcing.

Figure $2 \mathrm{~d}$ shows the mean AOD spectra for the wintertime clear sky days at KGP, KOL, and VSP. The Angstrom

Table 1. List of aerosol parameters and the study period over various study locations.

\begin{tabular}{c|c|c|c|c}
\hline \multirow{2}{*}{ Instruments } & Obtained aerosol parameters & \multicolumn{3}{|c}{ Data period at the sites of observation } \\
\cline { 4 - 5 } & VSP & \multicolumn{2}{c}{ KGP } & KOL \\
\hline $\begin{array}{c}\text { MICROTOPS II } \\
\text { Sun Photometer }\end{array}$ & $\begin{array}{c}\text { Spectral AOD at five wavelengths (Half hourly } \\
\text { measurements during day time) }\end{array}$ & $\begin{array}{c}\text { 2 to 27 Dec 2004 } \\
\text { (winter) }\end{array}$ & $\begin{array}{c}28 \text { to } 30 \text { Dec 2004 } \\
\text { (winter) }\end{array}$ \\
\cline { 1 - 1 } Aethalometer & $\begin{array}{c}\text { Real time surface BC mass concentration } \\
\text { (5-minute interval, round the clock) }\end{array}$ & $\begin{array}{c}\text { Winter and summer } \\
\text { months of 2005 }\end{array}$ & 2 to 27 Dec 2004 & 28 to 30 Dec 2004 \\
\cline { 1 - 2 } $\begin{array}{c}\text { Micro Pulse Lidar } \\
\text { (MPL) }\end{array}$ & $\begin{array}{c}\text { Backscatter intensity profiles (round the clock } \\
\text { once a week, 10 sec time resolution) }\end{array}$ & & 2 to 27 Dec 2004 & 28 to 30 Dec 2004 \\
\hline
\end{tabular}



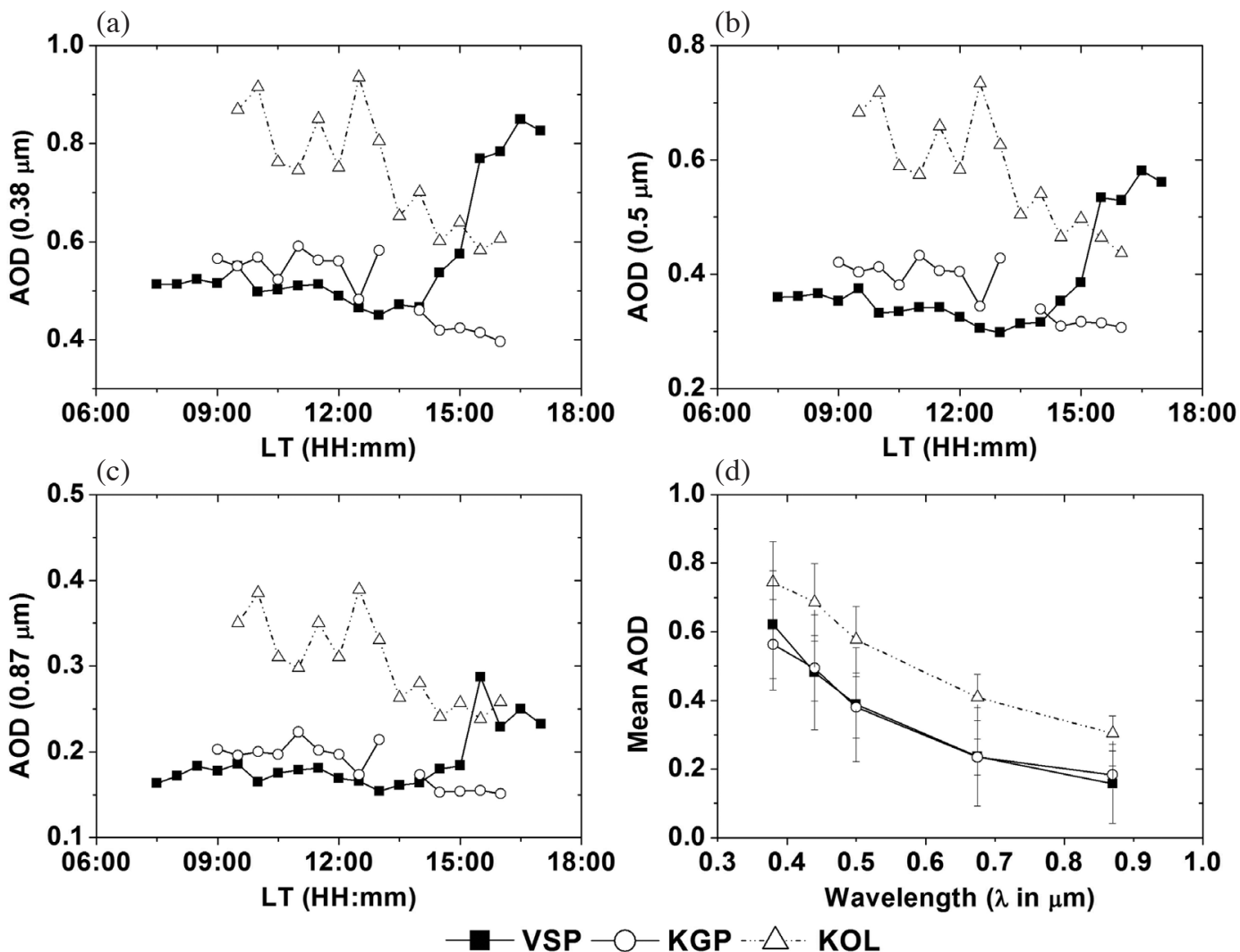

Fig. 2. Diurnal variation of aerosol optical depths over VSP, KGP, and KOL at (a) $0.38 \mu \mathrm{m}$, (b) $0.5 \mu \mathrm{m}$, and (c) $0.87 \mu \mathrm{m}$ on typical clear sky days during the study period. (d) Spectral variation of mean aerosol optical depth over VSP, KGP, and KOL.

size index $(\alpha)$ was observed to be high $\sim 1.7$ at VSP, $\sim 1.4$ at $\mathrm{KGP}$, and $\sim 1.1$ at KOL during the clear sky conditions in winter time, indicating the variability in the dominance of fine mode particles from location to location.

The mean spectral variation in AOD over VSP and KGP during the observation period remained almost similar with a slight variation in the shorter and longer wavelengths, while over KOL the spectral AOD was high indicating increased columnar abundance in all size regimes. Nair et al. (2007) reported that both the long range transport of aerosols from the west and/or the movement of the cool meteorological front from the west to east would be responsible for the day to day changes in the aerosol concentrations over KGP.

\subsection{Diurnal Variations of BC Mass Concentrations}

The mean diurnal near surface aerosol BC mass concentration variations (in $\mu \mathrm{g} \mathrm{m}^{-3}$ ) measured using an Aethalometer are shown in Fig. 3 for VSP for summer 2004, (No. of observation days: 116) and winter 2004 (No. of observation days: 82 days) seasons (upper panel) and KGP for clear and hazy sky conditions during winter 2004 (lower panel, no. of observation days: 27) along with the vertical bars representing $\pm 1 \sigma$ variation, which indicate significant and similar diurnal variations over VSP as well as over KGP during the winter months. VSP however shows significantly lower BC surface mass concentrations. The morning peak at KGP was around $0730 \mathrm{LT}$ with a $\mathrm{BC}$ mass concentration of $\sim 21.0 \pm 6.82 \mu \mathrm{g} \mathrm{m}^{-3}$, gradually decreasing to a minimum of $7.5 \pm 3.68 \mu \mathrm{g} \mathrm{m}^{-3}$ during the afternoon hours followed by an increasing trend after the local sunset with a nocturnal peak of $\sim 20 \pm 5.73 \mu \mathrm{g} \mathrm{m}^{-3}$. Sreekanth et al. (2007) observed the winter morning peak at VSP to be around 0700 LT with BC mass concentration of $\sim 13.5 \mu \mathrm{g} \mathrm{m}^{-3}$ gradually decreasing to a minimum of $\sim 4.8 \mu \mathrm{g} \mathrm{m}^{-3}$ during the afternoon hours followed by an increasing trend after the local sunset with a nocturnal peak of $\sim 10.4 \mu \mathrm{g} \mathrm{m}^{-3}$ during the winter season.

During the summer months however, the BC surface mass concentrations were significantly lower due to the larger boundary layer depth and aerosols mixing within the boundary layer due to convection. The diurnal variations are associated with the combined effect of variations in production, surface meteorology and the associated boundary-layer dynamics. Since the atmospheric boundary layer becomes shallower during winter nights than during the day time and due to low wind speeds during this season, there is a rapid reduction in aerosols ventilation which results in aerosols confinement and a subsequent increase in the near surface mass concentrations during the night time. Shallow boundary layers during the winter season act as a capping inversion 


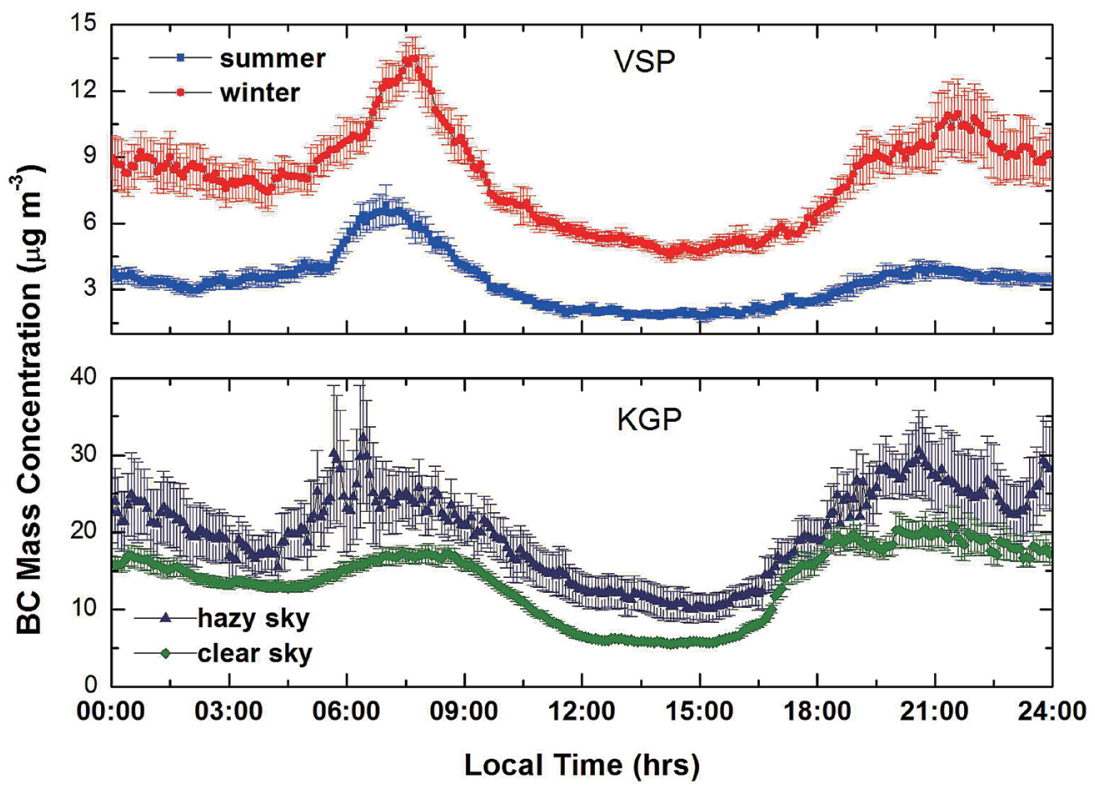

Fig. 3. Mean diurnal BC mass concentration variations during the summer and winter (upper panel) over VSP; during clear and hazy episodes in winter months over the KGP (bottom panel). (Color online only)

leading to aerosol accumulation in the near-surface regions. This is more acute in IGP regions, which experience severe $\mathrm{BC}$ aerosol loading due to bio mass burning and aerosols accumulation within the boundary layer. As night progresses, due to the reduction in the anthropogenic activity, there is a reduction in the mass concentrations during the early hours. The BC mass subsequently increases with the increase in anthropogenic activity during the morning hours. With the local sunrise and subsequent land surface heating, convective activity and vertical mixing build and the aerosol confinement breaks, leading to dispersion and a decrease in the surface concentration. Thus, the aerosol BC mass concentration shows large diurnal variations, which have serious implications on the radiative forcing estimation. This study is focused on the effect of this large $\mathrm{BC}$ accumulation within the boundary layer during the forenoon hours and the consequences therein on the accuracies in shortwave $\mathrm{BC}$ radiative forcing estimation in the backdrop of the normal average boundary layer altitude assumption during the day. We also used the MPL at VSP to study the qualitative altitudinal aerosol abundance distribution during different seasons to substantiate this supposition. The results are presented in the next section.

\subsection{Altitudinal Distribution of Aerosol Abundance as Observed Using MPL}

Figure 4 shows colour maps of aerosol backscatter intensity derived from MPL at VSP (on $8^{\text {th }}$ and $12^{\text {th }}$ November), KGP (on $8^{\text {th }}$ and $17^{\text {th }}$ December), and KOL (on $28^{\text {th }}$ and $29^{\text {th }}$ December) during evening hours of LT. The profiles shown are corrected for range, overlap, and Rayleigh scattering. The analysis details are available in Niranjan et al. (2006). Significant aerosol backscatter seen over VSP and KGP was comparable up to an altitude of $2.3 \mathrm{~km}$, while over KOL the back-scatter intensity profiles significant aerosol populations extending to even higher altitudes. December 17 was a hazy day at KGP and there was a clear aerosol subsidence and strong aerosol backscatter restricted only to the lower altitudes.

During the daytime, the surface gets heated due to clear sky conditions and in the evening, the sudden cooling after sunset leads to the formation of a stable layer close to the surface, with an elevated residual layer of enhanced aerosol concentrations. The enhanced aerosol concentrations between 1.8 and $2.5 \mathrm{~km}$ altitudes on 28 December (over KOL) could possibly be due to aerosols entrainment above the boundary layer. However, a vital observation is that in $70 \%$ of the cases when high column AODs were observed over VSP, the high surface mass and BC mass concentrations measured by the Quartz Crystal Microbalance (QCM) and the Aethalometer respectively were associated with either aerosol subsidence restricting the aerosol ventilation and thereby increasing the near surface mass concentration or a strong backscatter in the form of an elevated layer. Extended aerosol back-scatter up to higher altitudes in the MPL profiles indicate good ventilation and associated reduction in the surface mass concentrations. The fact that the surface aerosol mass concentrations were not low at KOL and that the spectral AODs were high over the region indicate a strong aerosol load that may have significant regional radiative impacts. 


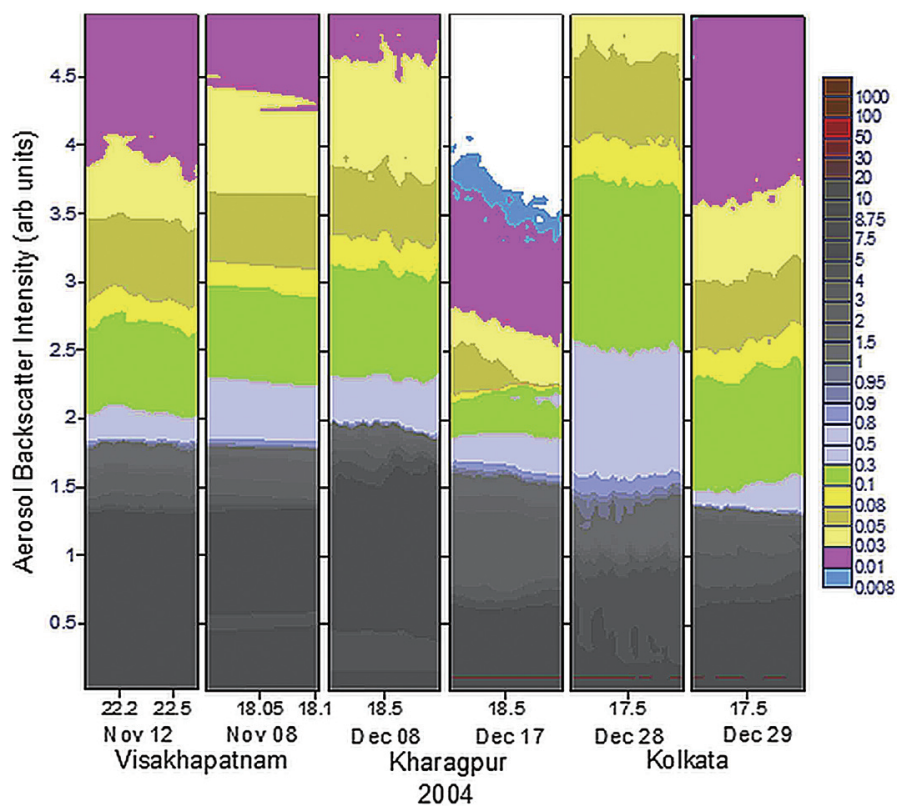

Fig. 4. Colour map of normalized aerosol backscatter intensity during evening/night time on typical days during winter months at VSP, KGP, and KOL. (Color online only)

To bring out the diurnal variation in the aerosol vertical distribution, the range and overlap corrected hourly mean vertical aerosol backscatter intensity profiles over VSP up to $3 \mathrm{~km}$ for the period 0000 to $1200 \mathrm{LT}$ (left panel) and 1300 to $0400 \mathrm{LT}$ (right panel) of 16 February 2005 (typical winter case) are shown in Figs. 5a and $\mathrm{b}$ along with the $\pm 1 \sigma$ deviation from the hourly mean value (horizontal bars). The hourly mean profile from 0000 to $0100 \mathrm{LT}$ is designated as 0030 and so on. Each hourly profile is an average of 360 vertical profiles derived, each derived from an average backscatter from 2500 laser pulses. Note that the back-scatter intensity scale ( $x$-axis) is in logarithmic units, as it varies over several orders of magnitude, while the altitude scale ( $y$-axis) is normal. It may be seen that during the night time the backscatter intensity is stronger at lower altitudes with a steep fall towards higher altitude. As the sun rises, a gradual increase in the back-scatter intensity occurs at higher altitudes, broadening the boundary layer. With further advance in time, due to the increase in surface temperature and the build-up of convective activity, the surface backscatter intensity decreases, indicating the vertical mixing of aerosols and ventilation. As a result of this, the altitude at which inversions takes place increases during the day time. During the night time relatively stronger backscatter was observed up to an altitude of $2 \mathrm{~km}$, while it was up to $3.5 \mathrm{~km}$ during the day time. Figure $5 \mathrm{~b}$ shows the hourly mean profiles from 1200 to 2400 LT, which depicts the reverse process in the evening hours. To quantify the intrusion of aerosols into higher altitudes during day time and the reverse process during night time, the e-scaling parameter (for the altitudinal range of $0-3 \mathrm{~km}$ ) was computed using the following equation
$I(z)=I_{o} \exp \left(-z / z_{o}\right)$

where $I(z)$ is the intensity of the Lidar backscatter signal as function of altitude $z, I_{o}$ is the value of intensity at the surface. Here $z_{o}$ is the e-scaling altitude which can be defined as the altitude at which the intensity reduces by e-times of its value (Léon et al. 2009). This parameter plays an important role in modelling aerosol optical properties (e.g., Hess et al. 1998). The diurnal variation of the scaling altitude is shown in Fig. 6.

The backscatter intensity (with subtracted background noise due to sun) from the Lidar is integrated up to $3 \mathrm{~km}$ and termed as column aerosol burden in the present study. The percentage contribution of near surface aerosols (aerosols below $1 \mathrm{~km}$ ) as derived from Lidar (integrated back scatter intensity up to $1 \mathrm{~km}$ ) to column aerosol burden is shown as the near surface contribution in Fig. 7 along with the scaling altitude. The scaling altitude increases with the Sun's activity (temperature) and reaches a peak of around $1 \mathrm{~km}$ at 1300 LT. It can be said that at this time the convective activity and turbulent mixing reach their peak values. Near surface aerosols contributed as low as $45 \%$ to the column burden after sunrise, while their contribution is around $65 \%$ after sunset. This is in conformity with the rapid reduction in the ventilation of aerosols, which results in their confinement and subsequent increase in the near-surface backscatter intensity during night times.

Figure 7 shows plots of the diurnal hourly mean backscatter intensity variations at two typical altitudes. The two altitudes are selected such that one $(200 \mathrm{~m})$ is below the 
(a)

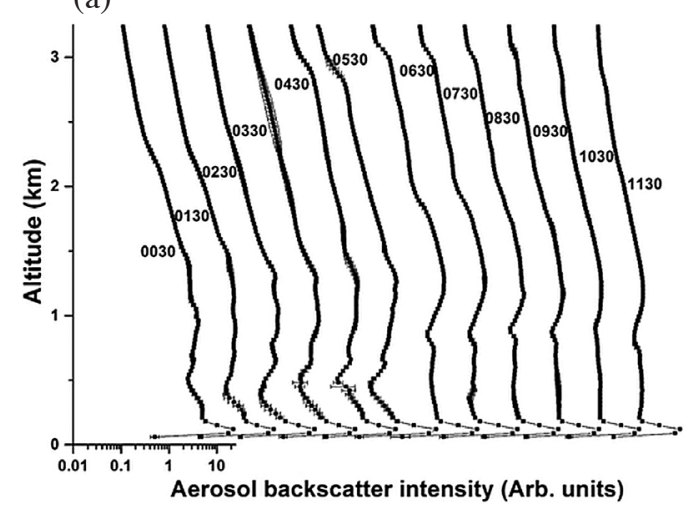

(b)

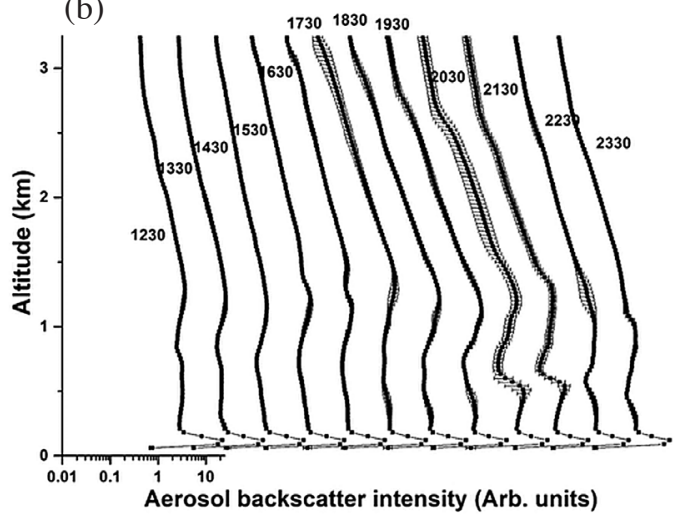

Fig. 5. Hourly mean aerosol back scatter intensity profiles (VSP) for $16^{\text {th }}$ February 2015 from $0000-1200 \mathrm{hr}$ (a), from 1300 - $2400 \mathrm{hr}$ (b).

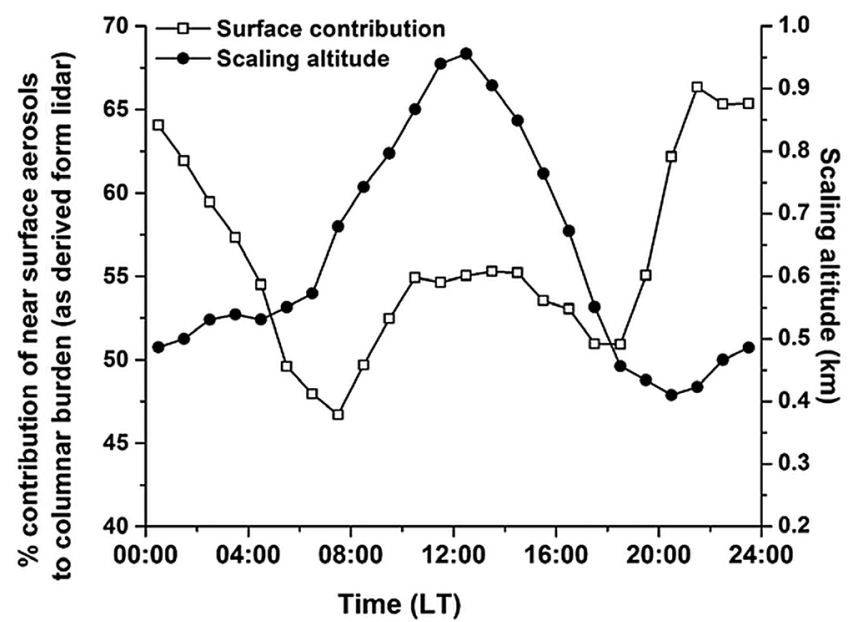

Fig. 6. Diurnal variation in percentage contribution of near surface aerosol to the column aerosol burden (both derived from Lidar back scatter intensity) along with Lidar derived aerosol scale altitude.

boundary layer height and the other one $(1400 \mathrm{~m})$ is above the boundary layer height round the clock. When there is a boundary layer subsidence, the aerosol population is compressed to the lower altitudes for example during nights that reflects an increase in the $200 \mathrm{~m}$ altitude while during day time when the convective activity sets in and the capping inversions are broken, there will be aerosol ventilation and hence there will be a decrease in aerosol population at the near surface level and increase at higher altitudes. This suggests strong altitude aerosol content redistribution in accordance with the boundary layer dynamics.

This suggests strong altitudinal aerosol content redistribution in accordance with the boundary layer dynamics. The examination of all diurnal cases falls in line with the above observations. Between $0000 \mathrm{LT}$, and sunrise, the surface contribution decreases probably because of the decrease in local anthropogenic activity giving rise to minimum \% contribution to near surface aerosol around the local sunrise. Due to the increase in anthropogenic activity, the \% contribution

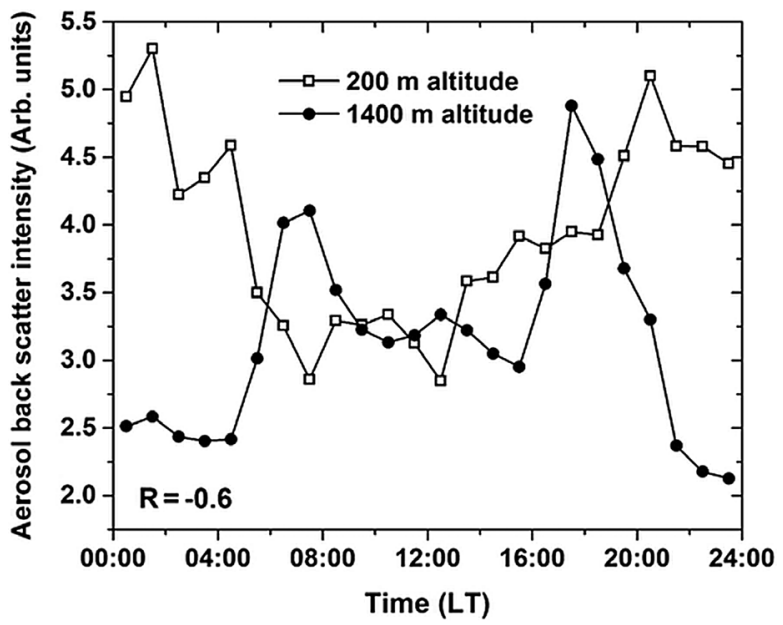

Fig. 7. Diurnal variation in Lidar back scatter intensity at two typical altitudes (200 and $1400 \mathrm{~m}$ ).

increases thereafter. Sometimes, aerosol stratification in the nocturnal lower troposphere is fairly common and can be attributed to stratified turbulence in that region (Parameswaran et al. 1997). Aerosol accretion occurs in stable regions and aerosols depletion occurs in turbulent zone embedded in a stable region. The aerosol concentration near the surface is strongly influenced by synoptic atmospheric boundary layer meteorology (Parameswaran et al. 2004). The secondary peak observation at $1400 \mathrm{~m}$ altitude could possibly be due to aerosol accretion within the stable boundary layer.

Utilizing the MPL backscatter profiles, boundary-layers heights are derived for both the locations (VSP and KGP), which are further incorporated in the offline aerosol models (more details in the following section) for the estimation of aerosol columnar optical properties and its radiative forcing. The boundary-layer height is considered as the transition zone base i.e., the interface between the mixed layer and the free troposphere (Flamant et al. 1997), a definition associated with the first derivative approach. It is considered that 
the potential temperature nearly remains steady within the boundary layer and the top of the boundary layer is marked by a sudden change in the lapse rate. We have evaluated the boundary layer height using the second derivative approach where in the minimum point of the 9-point smoothed second derivative profile with $30-\mathrm{m}$ resolution is considered as the top of the boundary layer (Chen et al. 2001; Niranjan et al. 2006). Mean diurnal variation in the boundary-layer height as derived from MPL observations over VSP during winter and summer are shown in Fig. 8. A comparison of Figs. 6 and 8 for the winter season clearly show how the boundary layer dynamics control the aerosol surface contribution and the scaling altitude. We plotted the mean aerosol backscatter intensity in Fig. 9 as a function of altitude for the months of January 2005 (winter months) and June 2005 (summer months) to bring this point out more clearly.

\section{SENSITIVITY OF BC RADIATIVE FORCING TO AEROSOL VERTICAL STRUCTURE}

Most of the information on the aerosol $\mathrm{BC}$ is derived from surface measurements and its shortwave radiative forcing estimation is done incorporating the daytime average $\mathrm{BC}$ surface mass concentration with knowledge on the vertical structure of the aerosols. The diurnal MPL backscatter observation profiles facilitated us to investigate the diurnal variation in the boundary-layer height over the study locations. The real time boundary-layer heights are incorporated into the Optical Aerosols and Clouds Properties (OPAC) model to derive the columnar aerosol optical properties. In the absence of such measurements, a mean boundary-layer altitude is assumed in the forcing estimation. Further, the surface BC exhibits significant diurnal variation depending on the season. Therefore, taking a diurnally-averaged BC mass concentration in the radiative forcing estimation may

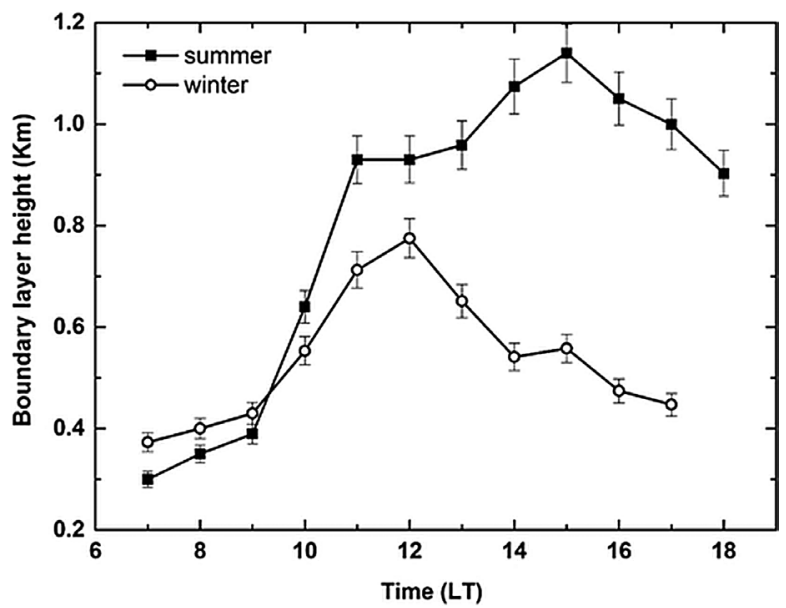

Fig. 8. Mean Diurnal variation in Boundary layer altitude (over VSP) as derived from MPL data. lead to significant errors. Secondly, assuming a mean altitude for the boundary layer height would imply that the BC is uniformly mixed throughout the layer and throughout the daytime. However, the boundary layer altitude also shows significant seasonal and diurnal variability (Fig. 7), thereby making the incorporation of the time variability of $\mathrm{BC}$ concentration and boundary-layer height important. In this context, we thought it would be appropriate to investigate how the radiative forcing estimation depends on the diurnal variability in the boundary layer altitude.

The OPAC aerosol model developed by Hess et al. (1998) was used in estimating the optical properties of the aerosols in this study. The optical and radiative properties derived from the above model were then fed to the Santa Barbara DISORT Atmospheric Radiative Transfer model (SBDART) developed by Ricchiazzi et al. (1998) to derive the aerosol radiative forcing. More details on the configuration of the above models are detailed elsewhere and are not repeated here (Niranjan et al. 2007, 2012). To evaluate the radiative forcing sensitivity to boundary layer dynamics, we estimated the diurnal mean $\mathrm{BC}$ forcing incorporating the mean boundary layer height instead of its real time variation. Table 2 shows how the computed $\mathrm{BC}$ radiative forcing changes (for VSP) with the type of inputs fed to the forcing algorithm.

It may be observed from this that during the winter months when the aerosol confinement takes place within the shallow boundary layer, the $\mathrm{BC}$ atmospheric forcing is largely overestimated if the diurnal change in the boundary layer altitude is not included in the atmospheric forcing computation and the error could be quite large. In Table 3, we consolidated the percent over-estimation of atmospheric forcing if we ignore the boundary-layer altitude time variation for VSP for the summer and winter months and for KGP for the winter months which clearly brings out the

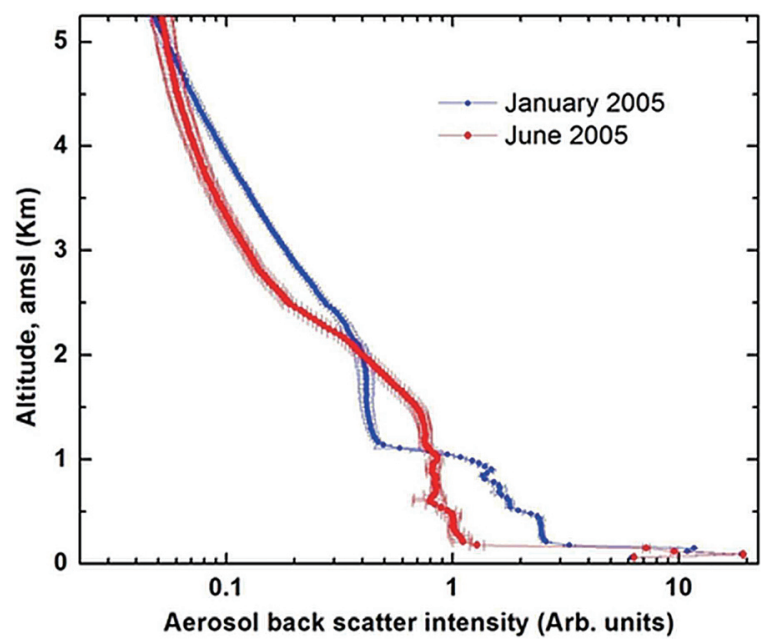

Fig. 9. Monthly mean aerosol back scatter intensity as a function of altitude for January (blue) and June (red) 2005. (Color online only) 
Table 2. Seasonal mean BC aerosol radiative forcing estimated with and without incorporating diurnal variations in the mixed layer heights.

\begin{tabular}{|c|c|c|c|c|c|c|c|c|c|}
\hline \multirow{2}{*}{$\begin{array}{l}\text { Black Carbon aerosol radiative forcing } \\
\qquad\left(\mathrm{W} \mathrm{m}^{-2}\right)\end{array}$} & \multicolumn{3}{|c|}{ Summer } & \multicolumn{3}{|c|}{ Winter } & \multicolumn{3}{|c|}{ Monsoon } \\
\hline & \begin{tabular}{|c|}
$\begin{array}{c}\text { Atmospheric } \\
\text { forcing }\end{array}$ \\
\end{tabular} & $\begin{array}{c}\text { TOA } \\
\text { forcing }\end{array}$ & $\begin{array}{l}\text { Surface } \\
\text { forcing }\end{array}$ & \begin{tabular}{|c|}
$\begin{array}{c}\text { Atmospheric } \\
\text { forcing }\end{array}$ \\
\end{tabular} & $\begin{array}{c}\text { TOA } \\
\text { forcing }\end{array}$ & $\begin{array}{l}\begin{array}{l}\text { Surface } \\
\text { forcing }\end{array} \\
\end{array}$ & \begin{tabular}{|c|}
$\begin{array}{c}\text { Atmospheric } \\
\text { forcing }\end{array}$ \\
\end{tabular} & $\begin{array}{c}\text { TOA } \\
\text { forcing }\end{array}$ & $\begin{array}{l}\text { Surface } \\
\text { forcing }\end{array}$ \\
\hline $\begin{array}{c}\text { Mean zenith-wise forcing considering } \\
\text { instantaneous BC mass concentration for } \\
\text { each zenith, keeping average mixed layer } \\
\text { height }\end{array}$ & 19.46 & 3.72 & -16.21 & 44.48 & 7.85 & -36.63 & 10.62 & 3.56 & -7.06 \\
\hline $\begin{array}{l}\text { Mean zenith-wise forcing considering } \\
\text { instantaneous BC mass concentration for } \\
\text { each zenith, incorporating mixed layer } \\
\text { height variations as derived from LIDAR }\end{array}$ & 16.33 & 3.22 & -12.83 & 26.9 & 4.86 & -22.04 & \multicolumn{3}{|c|}{$\begin{array}{l}\text { Lidar data not available due to } \\
\text { rains }\end{array}$} \\
\hline
\end{tabular}

Table 3. Figures showing the percentage over-estimation of atmospheric forcing due to the non-incorporation of the real-time boundary layer height variations in the offline models.

\begin{tabular}{c|c}
\hline Station & \% over-estimation [(atmospheric forcing from last row of Table 2/atmospheric forcing from first row of Table 2) $\times$ 100] \\
\hline VSP Summer month & 7.3 \\
\hline VSP Winter month & 69.8 \\
\hline KGP winter month & 72.6 \\
\hline
\end{tabular}

care required in respecting the boundary layer parameters in aerosol radiative forcing estimation to reduce the errors in such efforts.

\section{CONCLUSIONS}

Recent studies have shown that strong diurnal variations in the aerosol characteristics affect the DARF estimations. The error estimates under these conditions are also found to be dependent on the length of the dataset used. These arguments motivated us to carry out the present analysis, in which, we quantitatively assessed the errors in the diurnally averaged $\mathrm{BC}$ radiative forcing estimated using average aerosol and boundary layer characteristics. Measurements show strong diurnal variations in the boundary layer height and $\mathrm{BC}$ mass concentrations (owing to the boundary layer evolutions) over the study locations. Vertical redistribution of aerosols is also evident from the Lidar profiles. Near real time aerosol and boundary layer heights are integrated into offline radiative forcing models to estimate $\mathrm{BC}$ radiative forcing. These error estimations are carried out for summer and winter seasons over VSP, while the estimates are for winter season over KGP. The results obtained articulate that the forcing estimates are overestimated by $7-70 \%$ when the average conditions are incorporated in the models. Radiative forcing results were not presented for KOL due to unavailability in the diurnal Lidar measurements. These results warrant that the incorporation of time resolved boundary layer heights in the aerosol radiative forcing estimation will be a step further for attaining more accurate aerosol forcing computation.
Acknowledgements The authors express their thanks to Dr. K. Krishna Moorthy of SPL, VSSC for providing the BC data from Kharagpur for November 2004. This work is supported by ISRO-Geosphere-Biosphere programme under ARFI project.

\section{REFERENCES}

Babu, S. S. and K. K. Moorthy, 2002: Aerosol black carbon over a tropical coastal station in India. Geophys. Res. Lett., 29, doi: 10.1029/2002GL015662. [Link]

Babu, S. S., S. K. Satheesh, and K. K. Moorthy, 2002: Aerosol radiative forcing due to enhanced black carbon at an urban site in India. Geophys. Res. Lett., 29, doi: 10.1029/2002GL015826. [Link]

Bauer, S. E., S. Menon, D. Koch, T. C. Bond, and K. Tsigaridis, 2010: A global modeling study on carbonaceous aerosol microphysical characteristics and radiative effects. Atmos. Chem. Phys., 10, 7439-7456, doi: 10.5194/acp-10-7439-2010. [Link]

Boucher, O., D. Randall, P. Artaxo, C. Bretherton, G. Feingold, P. Forster, V. M. Kerminen, Y. Kondo, H. Liao, U. Lohmann, P. Rasch, S. K. Satheesh, S. Sherwood, B. Stevens, and X. Y. Zhang, 2013: Clouds and aerosols. In: Stocker, T. F., D. Qin, G. K. Plattner, M. Tignor, S. K. Allen, J. Boschung, A. Nauels, Y. Xia, V. Bex, and P. M. Midgley (Eds.), Climate Change 2013: The Physical Science Basis, Contribution of Working Group I to the Fifth Assessment Report of the Intergovernmental Panel on Climate Change, Cambridge University Press, Cambridge, United Kingdom and 
New York, NY, USA, 571-657.

Bush, B. C. and F. P. J. Valero, 2003: Surface aerosol radiative forcing at Gosan during the ACE-Asia campaign. J. Geophys. Res., 108, doi: 10.1029/2002JD003233. [Link]

Chen, W., H. Kuze, A. Uchiyama, Y. Suzuki, and N. Takeuchi, 2001: One-year observation of urban mixed layer characteristics at Tsukuba, Japan using a micro pulse lidar. Atmos. Environ., 35, 4273-4280, doi: 10.1016/S1352-2310(01)00181-9. [Link]

Devara, P. C. S., G. Pandithurai, P. E. Raj, and S. Sharma, 1996: Investigations of aerosol optical depth variations using spectroradiometer at an urban station, Pune, India. J. Aerosol. Sci., 27, 621-632, doi: 10.1016/00218502(95)00550-1. [Link]

Eck, T.F., B. N. Holben, J. S. Reid, O. Dubovik, A. Smirnov, N. T. O'Neill, I. Slutsker, and S. Kinne, 1999: Wavelength dependence of the optical depth of biomass burning, urban, and desert dust aerosols. J. Geophys. Res., 104, 31333-31349, doi: 10.1029/1999JD900923. [Link]

Flamant, C., J. Pelon, P. H. Flamant, and P. Durand, 1997: Lidar determination of the entrainment zone thickness at the top of the unstable marine atmospheric boundary layer. Bound.-Layer Meteor., 83, 247-284, doi: 10.1023/A:1000258318944. [Link]

Golaz, J. C., M. Salzmann, L. J. Donner, L. W. Horowitz, Y. Ming, and M. Zhao, 2011: Sensitivity of the aerosol indirect effect to subgrid variability in the cloud parameterization of the GFDL atmosphere general circulation model AM3. J. Climate, 24, 3145-3160, doi: 10.1175/2010JCLI3945.1. [Link]

Hansen, A. D. A., 1996: Magee Scientific Aethalometer User's Guide, Magee scientific, Berkely, Calif.

Henze, D. K., D. T. Shindell, F. Akhtar, R. J. D. Spurr, R. W. Pinder, D. Loughlin, M. Kopacz, K. Singh, and C. Shim, 2012: Spatially refined aerosol direct radiative forcing efficiencies. Environ. Sci. Technol., 46, 95119518, doi: 10.1021/es301993s. [Link]

Hess, M., P. Koepke, and I. Schult, 1998: Optical properties of aerosols and clouds: The software package OPAC. Bull. Amer. Meteorol. Soc., 79, 831-844, doi: 10.117 5/1520-0477(1998)079<0831:OPOAAC >2.0.CO;2. [Link]

Hoose, C., J. E. Kristjánsson, T. Iversen, A. Kirkevåg, Ø. Seland, and A. Gettelman, 2009: Constraining cloud droplet number concentration in GCMs suppresses the aerosol indirect effect. Geophys. Res. Lett., 36, L12807, doi: 10.1029/2009GL038568. [Link]

Ichoku, C., R. Levy, Y. J. Kaufman, L. A. Remer, R. R. Li, V. J. Martins, B. N. Holben, N. Abuhassan, I. Slutsker, T. F. Eck, and C. Pietras, 2002: Analysis of the performance characteristics of the five-channel Microtops II Sun photometer for measuring aerosol optical thick- ness and precipitable water vapor. J. Geophys. Res., 107, doi: 10.1029/2001JD001302. [Link]

Kirchstetter, T. W., T. Novakov, and P. V. Hobbs, 2004: Evidence that the spectral dependence of light absorption by aerosols is affected by organic carbon. J. Geophys. Res., 109, D21208, doi: 10.1029/2004JD004999. [Link]

Léon, J. F., Y. Derimian, I. Chiapello, D. Tanré, T. Podvin, B. Chatenet, A. Diallo, and C. Deroo, 2009: Aerosol vertical distribution and optical properties over M'Bour $\left(16.96^{\circ} \mathrm{W} ; 14.39^{\circ} \mathrm{N}\right)$, Senegal from 2006 to 2008. Atmos. Chem. Phys., 9, 9249-9261, doi: 10.5194/acp-99249-2009. [Link]

Madhavan, B. L., K. Niranjan, V. Sreekanth, M. M. Sarin, and A. K. Sudheer, 2008: Aerosol characterization during the summer monsoon period over a tropical coastal Indian station, Visakhapatnam. J. Geophys. Res., 113, D21208, doi: 10.1029/2008JD010272. [Link]

Morys, M., F. M. Mims III, S. Hagerup, S. E. Anderson, A. Baker, J. Kia, and T. Walkup, 2001: Design, calibration, and performance of MICROTOPS II handheld ozone monitor and Sun photometer. J. Geophys. Res., 106, 14573-14582, doi: 10.1029/2001JD900103. [Link]

Nair, V. S., K. K. Moorthy, D. P. Alappattu, P. K. Kunhikrishnan, S. George, P. R. Nair, S. S. Babu, B. Abish, S. K. Satheesh, S. N. Tripathi, K. Niranjan, B. L. Madhavan, V. Srikant, C. B. S. Dutt, K. V. S. Badarinath, and R. R. Reddy, 2007: Wintertime aerosol characteristics over the Indo-Gangetic Plain (IGP): Impacts of local boundary layer processes and longrange transport. J. Geophys. Res., 112, D13205, doi: 10.1029/2006JD008099. [Link]

Niranjan, K., V. Sreekanth, B.L. Madhavan, and K. K. Moorthy, 2006: Wintertime aerosol characteristics at a north Indian site Kharagpur in the Indo-Gangetic plains located at the outflow region into Bay of Bengal. J. Geophys. Res., 111, D24209, doi: 10.1029/2006JD007635. [Link]

Niranjan, K., B. L. Madhavan, and V. Sreekanth, 2007: Micro pulse lidar observation of high altitude aerosol layers at Visakhapatnam located on the east coast of India. Geophys. Res. Lett., 34, L03815, doi: 10.1029/2006GL028199. [Link]

Niranjan, K., T. A. Devi, B. Spandana, V. Sreekanth, and B. L. Madhavan, 2012: Evidence for control of black carbon and sulfate relative mass concentrations on composite aerosol radiative forcing: Case of a coastal urban area. J. Geophys. Res., 117, D05205, doi: 10.1029/2011JD016752. [Link]

Parameswaran, K., K. Rajeev, and K. Sen Gupta, 1997: An observational study of night time aerosol concentrations in the lower atmosphere at a tropical coastal station. J. Atmos. Sol.-Terr. Phys., 59, 1727-1737, doi: 10.1016/S1364-6826(97)00013-8. [Link] 
Parameswaran, K., S. V. Sunilkumar, K. Rajeev, P. R. Nair, and K. K. Moorthy, 2004: Boundary layer aerosols at Trivandrum tropical coast. Adv. Space Res., 34, 838844, doi: 10.1016/j.asr.2003.08.059. [Link]

Porter, J. N., M. Miller, C. Pietras, and C. Motell, 2001: Ship-based Sun photometer measurements using Microtops Sun Photometers. J. Atmos. Ocean. Technol., 18, 765-774, doi: 10.1175/1520-0426(2001)018<0765 :SBSPMU>2.0.CO;2. [Link]

Ricchiazzi, P., S. Yang, C. Gautier, and D. Sowle, 1998: SBDART: A research and teaching software tool for plane-parallel radiative transfer in the Earth's atmosphere. Bull. Amer. Meteorol. Soc., 79, 2101-2114, doi: 10.1175/1520-0477(1998)079<2101:SARATS >2 .0.CO;2. [Link]

Singh, R. P., S. Dey, S. N. Tripathi, V. Tare, and B. Holben, 2004: Variability of aerosol parameters over Kanpur, northern India. J. Geophys. Res., 109, D23206, doi: 10.1029/2004JD004966. [Link]

Smith, S. J., H. Pitcher, and T. M. L. Wigley, 2001: Global and regional anthropogenic sulfur dioxide emissions.
Global Planet. Change, 29, 99-119, doi: 10.1016/ S0921-8181(00)00057-6. [Link]

Sreekanth, V., K. Niranjan, and B. L. Madhavan, 2007: Radiative forcing of black carbon over eastern India. Geophys. Res. Lett., 34, L17818, doi: 10.1029/2007GL030377. [Link]

Stevens, B., 2015: Rethinking the lower bound on aerosol radiative forcing. J. Climate, 28, 4794-4819, doi: 10.1175/JCLI-D-14-00656.1. [Link]

Wang, C., 2004: A modeling study on the climate impacts of black carbon aerosols. J. Geophys. Res., 109, D03106, doi: 10.1029/2003JD004084. [Link]

Wang, C., 2007: Impact of direct radiative forcing of black carbon aerosols on tropical convective precipitation. Geophys. Res. Lett., 34, L05709, doi: 10.1029/2006GL028416. [Link]

Wang, Z., D. Liu, Y. Wang, Z. Wang, and G. Shi, 2015: Diurnal aerosol variations do affect daily averaged radiative forcing under heavy aerosol loading observed in Hefei, China. Atmos. Meas. Tech., 8, 2901-2907, doi: 10.5194/amt-8-2901-2015. [Link] 